\title{
Understanding Midwives' Perspective on Care of Post Cesarean Section Women at the University Teaching Hospital-Women and Newborn, Lusaka
}

\author{
Priscar Sakala Mukonka1 (i), Patricia Katowa Mukwato', Conceptor Namukolo Kwaleyela1, \\ Clara Haruzivishe ${ }^{2}$, Margaret C. Maimbolwa1 \\ ${ }^{1}$ School of Nursing Sciences, University of Zambia, Lusaka, Zambia \\ ${ }^{2}$ Department of Nursing Science, College of Health Sciences, University of Zimbabwe, Harare, Zimbabwe \\ Email:pmukonka@yahoo.com, patriciakatowa@gmail.com, concept.kwaleyela@unza.zm, claraopha@gmail.com, \\ mmaimbolwa@yahoo.com, Margaret.maimbolwa@unza.zm
}

How to cite this paper: Mukonka, P.S., Mukwato, P.K., Kwaleyela, C.N., Haruzivishe, C. and Maimbolwa, M.C. (2018) Understanding Midwives' Perspective on Care of Post Cesarean Section Women at the University Teaching Hospital-Women and Newborn, Lusaka. Open Journal of Nursing, 8, 918-939.

https://doi.org/10.4236/ojn.2018.812069

Received: December 9, 2018

Accepted: December 26, 2018

Published: December 29, 2018

Copyright (c) 2018 by authors and Scientific Research Publishing Inc. This work is licensed under the Creative Commons Attribution International License (CC BY 4.0).

http://creativecommons.org/licenses/by/4.0/

\section{c) (i) Open Access}

\begin{abstract}
Background: A cesarean section is a major obstetric surgical procedure performed for the purpose of delivering a live baby when vaginal delivery would put the mother and the baby at risk due to complications of pregnancy, labour and delivery. Although caesarean section is a life saving procedure, it is associated with a number of risks or problems in the postoperative period. The aim of the study was to understand the Midwives' perspective on the care of postpartum mothers who had cesarean section at the University Teaching Hospital-Women and Newborn in Lusaka District. Methods: A descriptive cross sectional survey was conducted at the University Teaching Hospital-Women and Newborn in Lusaka. 51 Midwives working in postnatal wards were consecutively selected to participate in the study. Data was collected using a self administered questionnaire with a 4 point Likert scale and also some closed and open ended questions. SPSS version 20 statistical package was used to analyse data, expressed as descriptive summary measures. Results: All the 51 Midwives were female and they scored themselves highly on a 4 point Likert scale as always performing all the immediate post-operative care on the postpartum mothers who had a caesarean section while the score was much lower during the subsequent post-operative period. Staffing levels and medical-surgical materials were found to be low and affect care of Postpartum mothers (P-0.050). The majority (94.2\%) of the Midwives also indicated that $\mathrm{C}$-section mothers were not given any form of written materials or standardized instructions to take home as reference material during the
\end{abstract}


Information, Education Communication sessions on discharge (P-0.001) and home/domiciliary visits to postpartum mothers who had C-sections on postpartum were not being undertaken. Conclusion: There was need to improve the care rendered to the postpartum women who had complicated labour and delivery including caesarean sections in order to promote good health and to prevent postpartum complications.

\section{Keywords}

Postpartum Mothers/Women, Postnatal/Postpartum Care, Cesarean Section, Practices, Midwives

\section{Introduction}

A caesarean section (C-Section) is a surgical procedure performed for the purpose of extracting a viable foetus through an incision in the abdominal wall and the uterus [1]. It is a major obstetric surgical procedure performed for the purpose of delivering a live baby when vaginal delivery would put the mother and the baby at risk due to complications of pregnancy, labour and delivery thereby saving lives of women and their newborns.

According to [2] complications may arise in 20 percent of women although childbirth is considered to be a normal physiological process. For some of the women with complications, they may proceed to deliver vaginally with or without instrumental assistance but for others, a c-section may be necessary to save the lives of either the baby or the mother or both. The operation can be performed either under general or epidural or spinal anaesthesia [1] [3]. The complications which may lead to a woman undergoing caesarean section (c-section) which in other terms are called indications of $\mathrm{C}$-section may be classified into three and these may be: maternal, foetal and obstetrical [1] [4].

Although a caesarean section is a life saving procedure, it is associated with a number of risks or problems in the postoperative period which may also be classified as maternal and foetal. Maternal problems may include heamorrhage, post operative pain, wound infection, incisional hernias, wound gapping, puerperal sepsis among others while foetal complications may include respiratory distress syndrome, birth injuries, transient lung syndrome among others [1] [5]. These risks/problems are six times more likely to occur than in vaginal delivery and fifty times more if a caesarean is performed in an emergency than if it was elective. Often a number of days are required in the hospital to recover sufficiently to return home, about three to five days and the healing process takes longer from about six weeks than in vaginal birth [6].

It is estimated that 340,000 maternal deaths occur worldwide each year in low-income countries and $61 \%$ of these maternal deaths occur during the first six weeks after birth, and nearly half of those deaths take place during the first 
week after delivery [7] [8] [9]. In the Sub-Saharan Africa including Zambia, many women do not have access to health care during early postnatal period putting them at high risk of illness and death [10] [11].

At the University Teaching Hospital-Women and Newborn, the average percentage of complicated deliveries of the total deliveries from January 2017 up to the first quarter of 2018 was 36 percent. An average of 33 percent of the total complicated cases were delivered by c-section, while an average of 3.42 percent were assisted deliveries [12] [13]. Although this seems to be too high, this is because the hospital is a referral centre and receives complicated cases from the surrounding areas and it is not representative of the national rate which is currently very low, at 4.4 percent, lower than the average Sub Saharan Africa which is at 7.9 percent and that of the World Health Organisation recommendation of between 10 to 15 percent [7] [12] [14] [15]. This is because Zambian women still experience problems in accessing skilled care during labour and delivery. Maternal mortality rate for Zambia is still unacceptably high at 398 women per 100,000 live births [14]. Other complications encountered by mothers post-operatively may include pyrexia and wound infections [16].

Bearing in mind that all women who had c-section would have under gone through a major abdominal surgery and although majority of them are strong and healthy and therefore heal remarkably quickly, it is important to be knowledgeable of the healing process, the resources and the needs of the women for them to have a successful healing process. The first 24 hours after a Caesarean section are vital to the healing process, which continues in the days, weeks and months to come [17]. Therefore, good practice of nursing and midwifery care in post C-section women is very important for healing and consequently reduction of the incidence of postpartum complications brought about by C-Section [17] [18] [19].

A study of this nature has not been conducted at the University Teaching Hospital and in Zambia. Many studies have focused on the indications and prevalence of c-sections and a few on complications but not on the care postpartum women receive after c-section.

The aim of the study was to understand the Midwives' perspective on the care of postpartum mothers who had complicated delivery with special focus on cesarean section at the University Teaching hospital-Women and Newborn from admission to the postnatal wards until their discharge from the hospital.

\section{Materials and Methods}

The study was conducted at a University Teaching Hospital-Women and Newborn (UTH-WN) in Lusaka. It is the lead institution in maternal, reproductive health and newborn care and is a centre for teaching and research in the country. The hospital also acts as a referral hospital for the surrounding districts. It has a bed capacity of 453. In 2017, the hospital recorded a total of 16,275 deliveries of which 5075 were delivered by c-section, making a 31 percent of total 
c-section deliveries. Post-operatively, postpartum mothers are nursed in the four different postnatal wards for three or more days depending on the condition before they are discharged home.

The study was a descriptive quantitative cross sectional survey conducted in the four postnatal wards of the UTH-WN. The Hospital was purposively selected as a study site because it is the biggest referral hospital in the district of Lusaka and usually attends to different cases of complicated pregnancies and deliveries. All the four postnatal wards in the hospital formed sites for the study. During the month of August, 2017, a study population of 51 midwives was achieved by use of consecutive sampling technique. This entailed that all midwives who were found working in the selected sites were included in the study. The author worked hand in hand with the ward managers and periodically passed through the wards to distribute the questionnaires to midwives on duty and also to collect the completed ones which were previously distributed. That way, midwives who were previously on day off, night duty or short leave were also given an opportunity to participate in the study. There was 100 percent response rate as all the distributed questionnaires were completed and brought back.

Data were collected in August, 2017 using a self administered questionnaire, which was composed of three different sets of questions and these included a 4 point Likert scale questions (Always-3, Sometimes-2, Rarely-1 and Never-0), closed and open-ended questions. The questions aimed to assess Midwives' knowledge and practices in the care of postpartum women after cesarean sections admitted to postnatal wards from admission till discharge. The areas covered were: immediate and subsequent post-operative care, pain management, availability of resources (materials and staffing), Information, Communication and Education (IEC) and follow-up of postpartum women after discharge.

After completion of development of the data collection instrument, it was subjected for scrutiny by the supervisors who checked the questions whether they were valid enough to yield the intended responses according to the set objectives and advised on the necessary revisions to be made. This was followed by pretesting of the data collection instrument on midwives working in the postnatal ward at a General Hospital within the district of Lusaka. Pretesting of the instrument helped establish reliability of the instrument in that after analyzing the questionnaires, areas of inconsistencies were established, revised and retested. The revision of the questionnaires involved removing some repeated questions, those which were unclear or ambiguous and also rephrasing some questions. The revision of the questionnaire also ensured that questions were clear, concise, appropriate and consistent.

The proposal was presented at the graduate forum for expert scrutiny and input and after approval it was submitted to the Biomedical Research Ethics Committee of the University of Zambia. Having passed this stage, the proposal was later submitted to the National Research Council under the Ministry of Health and an approval was also obtained. Permission to collect data in the hos- 
pitals was sought and granted by the Senior Medical Superintendents at the UTH-WN and the General Hospital. Privacy, anonymity and confidentiality for participants were maintained and participation in study was purely voluntary.

Collected data were securely kept in a locked cupboard and only accessible to the researcher. Data was entered in a computer and analysed using SPSS version 20 computer statistical package. The demographic variables (age, level of education) were summarized using descriptive summary measures and inferential statistics: expressed as mean (standard deviation) for continuous variables and percentages/proportions for categorical variables.

Chi Square tests were conducted for categorical variables. The alpha level (p-value) test tested for significance of all the results. Statistic significance at 0.05 confidence interval and 95\% significance level was set.

Results were presented as frequency distribution tables. Likert scale results were summarised in frequency distribution tables with, "Always" scoring the highest mark-3, "Sometimes" scoring-2, and "Rarely" the lowest mark-1. A score of "Never" did not attract any mark-0. An average score for each category of care has also been computed on the 4 point Likert scale. The 4 point Likert scale (Always, Sometimes, Rarely and Never) indicated self assessment by midwives themselves on whether and how often they performed the caring activities in accordance with the selected variables.

The following variables assessed the different aspects of care from the time the mothers were admitted to the postnatal wards after c-section surgery until their discharge from the hospital: demographic characteristics, immediate post-operative care, subsequent post-operative care, pain management, mode of Information, Education and Communication (IEC) delivery, availability of resources (staffing and materials) and patient follow up after discharge (domiciliary/home visits).

In its uniqueness, the study afforded an opportunity to midwives working in the postnatal wards to give their unbiased perspective of the care of women who undergo c-section due to complications of labour and delivery. The women were admitted to postnatal wards from theatre until their discharge from the hospital. Many studies have proved that nurses and midwives could be relied upon to give their unbiased perspective of the care they give to patients on the wards [20] [21].

\section{Results}

\subsection{Demographic Characteristics of the Respondents}

A total of 51 Nurse-Midwives participated in the study and were all (100\%) females. Respondents were aged as follows: 2 (3.9) were below 20 years, 7 (13.7\%) were 20 - 29 years, $21(41.2 \%)$ were 30 - 39 years, 10 (19.6\%) were 40 - 49 years and $11(21.6 \%)$ were 50 years and above. As regards education level, majority 34 (66.7\%) had diplomas, 15 (29.2\%) had certificates and only 2 (3.9\%) had Bachelor's degree in nursing. In terms of designation, 34 (66.7\%) were Registered 
Nurse-Midwives, 14 (27.5\%) were certified or enrolled midwives and 3 (3.9\%) were either Nursing officers or ward in charges. Majority of the respondents 29 (56.9\%) had worked for less than one year in the postnatal wards followed by 18 (35.3\%) respondents who had worked between 1 - 5 years in the postnatal wards.

\subsection{Immediate Post Operative Care of Caesarean-Section Postpartum Mothers}

To assess how often Midwives performed the immediate post operative care on the mothers in the immediate post operative period, Midwives were asked to score themselves on the 4 point Likert scale with always performing the task represented by a score of 4 as the highest score and rarely performing the task represented by a score of 1 as the lowest score. A score of zero which represented never, did not attract any score. 44 (86.3\%) of the midwives scored themselves as always placing the patient in the recovery position immediately the patient was brought to the ward, 49 (96.1\%) scored themselves as always conducting observations of temperature, pulse, respirations and blood pressure as required, 48 (94.1\%) scored themselves as always maintaining and monitoring intravenous fluids and blood transfusion, (98.1\%) as always ensuring that urinary catheter was monitored and ensured flow of urine and took care of the catheter, 40 (78.4\%) always checked the incision for bleeding. The average score on the 4 point Likert scale for provision of immediate post operative care to women was 2.9 (Table 1).

\subsection{Subsequent Post Operative Care of Caesarean-Section Postpartum Mothers}

To assess the subsequent post-operative care of women after c-section, Midwives were asked to score themselves on the 4 point Likert scale on the following tasks they performed on the women: $39(76.5 \%)$ out of a total of 51 women scored themselves as always supporting with early breast feeding of the babies, 40 (78.4\%) scored as always supporting the women with early ambulation, 30 (58.8\%) scored themselves as always performing wound care on the c-section women, 15 (29.4\%) scored themselves as always supporting the women go to the bathroom, 6 $(11.9 \%)$ as always bed bathing women who were not able to do so, 9 (17.65) as always providing a big bath to mothers, 3 (5.9\%) always providing oral care and $26(51 \%)$ as always ensuring good nutrition for the women. A total average score on all items on the subsequent post-operative care on a 4 point Likert scale was 1.8 (Table 2).

\subsection{Management of Pain for Caesarean-Section Postpartum Mothers}

On pain management of women after a c-section, Midwives were asked to score themselves on different ways they managed pain using a 4 point Likert scale. Out of a total of 51 respondents, 19 (37.3\%) scored them as always giving opiods to 
Table 1. Immediate post operative care of caesarean-section postpartum mothers $\mathrm{N}=$ 51.

\begin{tabular}{|c|c|c|c|c|c|c|}
\hline & $\mathbf{N}$ & $\%$ & $\begin{array}{l}\text { Average } \\
\text { score }\end{array}$ & Mean & $\begin{array}{l}\text { Standard } \\
\text { deviation }\end{array}$ & $P$-value \\
\hline $\begin{array}{l}\text { Place in recovery } \\
\text { position }\end{array}$ & & & 2.8 & 2.84 & 0.418 & 0.687 \\
\hline Always & 44 & 86.3 & & & & \\
\hline Sometimes & 6 & 11.8 & & & & \\
\hline Rarely & 1 & 2.0 & & & & \\
\hline Never & 0 & 0 & & & & \\
\hline $\begin{array}{c}\text { Check } \\
\text { Temp/Pulse/Resp/BP }\end{array}$ & & & 2.9 & 2.94 & 0.311 & 0.388 \\
\hline Always & 49 & 96.1 & & & & \\
\hline Sometimes & 1 & 2.0 & & & & \\
\hline Rarely & 1 & 2.0 & & & & \\
\hline Never & 0 & 0 & & & & \\
\hline $\begin{array}{l}\text { Monitor fluids/blood } \\
\text { transfusion }\end{array}$ & & & 2.9 & 2.90 & 0.450 & 1.000 \\
\hline Always & 48 & 94.1 & & & & \\
\hline Sometimes & 2 & 3.9 & & & & \\
\hline Rarely & 0 & 0 & & & & \\
\hline Never & 1 & 2.0 & & & & \\
\hline $\begin{array}{l}\text { Maintain fluid } \\
\text { balance chart }\end{array}$ & & & 2.8 & 2.84 & 0.418 & 0.687 \\
\hline Always & 44 & 86.3 & & & & \\
\hline Sometimes & 6 & 11.8 & & & & \\
\hline Rarely & 1 & 2.0 & & & & \\
\hline Never & 0 & 0 & & & & \\
\hline $\begin{array}{c}\text { Care of } \\
\text { catheter/urine bag }\end{array}$ & & & 2.9 & 1.06 & 0.238 & 0.610 \\
\hline Always & 48 & 94.1 & & & & \\
\hline Sometimes & 3 & 5.9 & & & & \\
\hline Rarely & 0 & & & & & \\
\hline Never & 0 & & & & & \\
\hline Check incision site & & & 2.7 & 2.76 & 0.473 & 0.856 \\
\hline Always & 40 & 78.4 & & & & \\
\hline Sometimes & 10 & 19.6 & & & & \\
\hline Rarely & 1 & 2.0 & & & & \\
\hline Never & 0 & 0 & & & & \\
\hline \multicolumn{7}{|l|}{$\begin{array}{l}\text { Total Average } \\
\text { performance }\end{array}$} \\
\hline Always & 229 & 89.8 & 2.9 & & & \\
\hline Sometimes & 22 & 8.62 & & & & \\
\hline Rarely & 4 & 1.56 & & & & \\
\hline Never & 0 & 0 & & & & \\
\hline
\end{tabular}


Table 2. Subsequent post operative care of caesarean-section postpartum mothers $\mathrm{N}=$ 51.

\begin{tabular}{|c|c|c|c|c|c|c|}
\hline & $\mathbf{N}$ & $\%$ & $\begin{array}{l}\text { Average } \\
\text { score }\end{array}$ & Mean & $\begin{array}{l}\text { Standard } \\
\text { deviation }\end{array}$ & $P$-value \\
\hline $\begin{array}{l}\text { Support with } \\
\text { early } B / F\end{array}$ & & & 2.6 & 1.37 & 0.799 & 0.085 \\
\hline Always & 39 & 76.5 & & & & \\
\hline Sometimes & 8 & 15.7 & & & & \\
\hline Rarely & 1 & 2.0 & & & & \\
\hline Never & 3 & 5.9 & & & & \\
\hline $\begin{array}{l}\text { Support with } \\
\text { early ambulation }\end{array}$ & & & 1.9 & 1.27 & 0.607 & 0.793 \\
\hline Always & 40 & 78.4 & & & & \\
\hline Sometimes & 9 & 17.6 & & & & \\
\hline Rarely & 1 & 2.0 & & & & \\
\hline Never & 1 & 2.0 & & & & \\
\hline Wound care & & & 1.9 & 1.49 & 0.644 & 0.881 \\
\hline Always & 30 & 58.8 & & & & \\
\hline Sometimes & 17 & 33.3 & & & & \\
\hline Rarely & 4 & 7.8 & & & & \\
\hline Never & 0 & 0 & & & & \\
\hline $\begin{array}{l}\text { Support to go to } \\
\text { the bathroom }\end{array}$ & & & 1.9 & 1.78 & 0.577 & 1.000 \\
\hline Always & 15 & 29.4 & & & & \\
\hline Sometimes & 32 & 62.7 & & & & \\
\hline Rarely & 4 & 7.8 & & & & \\
\hline Never & 0 & 0 & & & & \\
\hline Bed bath & & & 1.3 & 2.69 & 1.010 & 0.904 \\
\hline Always & 6 & 11.8 & & & & \\
\hline Sometimes & 18 & 35.3 & & & & \\
\hline Rarely & 13 & 25.5 & & & & \\
\hline Never & 14 & 27.5 & & & & \\
\hline Big bath & & & 1.5 & 2.51 & 1.065 & 0.020 \\
\hline Always & 9 & 17.6 & & & & \\
\hline Sometimes & 20 & 39.2 & & & & \\
\hline Rarely & 9 & 17.6 & & & & \\
\hline Never & 13 & 25.5 & & & & \\
\hline Oral care & & & 1.1 & 2.90 & 0.922 & 0.222 \\
\hline Always & 3 & 5.9 & & & & \\
\hline Sometimes & 15 & 29.4 & & & & \\
\hline Rarely & 17 & 33.3 & & & & \\
\hline
\end{tabular}




\begin{tabular}{|c|c|c|c|c|c|c|}
\hline Continued & & & & & & \\
\hline Never & 16 & 31.4 & & & & \\
\hline Nutrition & & & 2.4 & 1.59 & 0.698 & 0.542 \\
\hline Always & 26 & 51.0 & & & & \\
\hline Sometimes & 21 & 41.2 & & & & \\
\hline Rarely & 3 & 5.9 & & & & \\
\hline Never & 1 & 2.0 & & & & \\
\hline $\begin{array}{c}\text { Total Average } \\
\text { Scores }\end{array}$ & & & 1.8 & & & \\
\hline Always & 83 & 32.55 & & & & \\
\hline Sometimes & 82 & 32.15 & & & & \\
\hline Rarely & 43 & 16.86 & & & & \\
\hline Never & 47 & 18.43 & & & & \\
\hline
\end{tabular}

the post C-section patients to alleviate the post-operative pain. $12(23.5 \%)$ indicated that they always reassured the mothers, (P-0.046), 13 (25.5\%) always administered opiods before patient recovered from effects of anesthesia ( $\mathrm{P}-0.022)$, $12(23.5 \%)$ scored themselves as always employing relaxation or diversion technique to relieve pain $(\mathrm{P}=0.010) .38(74.5 \%)$ respondents indicated that they administered opiods immediately after the patient recovered from effects of anaethesia, $21(41.2 \%)$ indicated that they would always give opiods when the patient complained of pain, $43(84.3 \%)$ indicated that they would always follow Doctors orders, $39(76.5 \%)$ indicated that they always administer opiods in the acute stage and then switch to non-opiods as pain lessens and 39 (76.5\%) scored themselves as always telling the mothers that pain was normal following c-section (P-0.049). The total average score on pain management was 2.2 on a 4 point Likert scale. The most common opiods used after surgery was pethidine (Table 3 ).

\subsection{How Information Education Communication Delivered to Postpartum Mothers on Discharge}

As regards IEC to the postpartum mothers following C-section, respondents were asked to score themselves on the different ways they delivered the ICE to postpartum mothers on discharge from the hospital. Out of a total of 51 (100\%) respondents, $42(82.4 \%)$ indicated that IEC was given to the mothers verbally on one to one, $38(74.5 \%)$ indicated that IEC was given verbally in a group. As to whether the midwives wrote some IEC on a piece of paper for the women to take home, majority 47 (92\%) indicated that it was not written on a piece of paper and $48(94.2 \%)$ also indicated that there were no standardized written instructions or IEC given to the mother to take home with her as reference materials (P-0.050) (Table 4).

\subsection{Availability of Staff for Care of Postpartum Women}

The respondents were asked questions in relation to staffing for the care of 
Table 3. Management of pain for caesarean-section postpartum mothers $\mathrm{N}=51$.

\begin{tabular}{|c|c|c|c|c|c|c|c|}
\hline & $\mathbf{N}$ & $\%$ & $\begin{array}{l}\text { Average } \\
\text { score }\end{array}$ & SD & Mean & Df & P-value \\
\hline Admin opiods & & & 1.8 & 1.155 & 2.16 & 2 & 0.608 \\
\hline Always & 19 & 37.3 & & & & & \\
\hline Sometimes & 16 & 31.4 & & & & & \\
\hline Rarely & 5 & 9.8 & & & & & \\
\hline Never & 11 & 21.6 & & & & & \\
\hline Relaxation/diversional tech & & & 1.7 & 1.031 & 2.27 & 3 & 0.010 \\
\hline Always & 12 & 23.5 & & & & & \\
\hline Sometimes & 20 & 39.2 & & & & & \\
\hline Rarely & 12 & 23.5 & & & & & \\
\hline Never & 7 & 13.7 & & & & & \\
\hline Reassure mother & & & 2.5 & 0.674 & 1.47 & 3 & 0.046 \\
\hline Always & 31 & 60.8 & & & & & \\
\hline Sometimes & 17 & 33.3 & & & & & \\
\hline Rarely & 2 & 3.9 & & & & & \\
\hline Never & 1 & 2.0 & & & & & \\
\hline $\begin{array}{l}\text { Admin opiods } \\
\text { before recovery }\end{array}$ & & & 1.4 & 1.084 & 2.54 & 3 & .022 \\
\hline Always & 13 & 25.5 & & & & & \\
\hline Sometimes & 14 & 27.5 & & & & & \\
\hline Rarely & 6 & 11.8 & & & & & \\
\hline Never & 18 & 35.2 & & & & & \\
\hline $\begin{array}{c}\text { Admin opiods } \\
\text { immediately after recovery }\end{array}$ & & & 2.6 & 0.987 & 2.49 & 2 & 0.171 \\
\hline Always & 38 & 74.5 & & & & & \\
\hline Sometimes & 7 & 13.7 & & & & & \\
\hline Rarely & 6 & 11.8 & & & & & \\
\hline Never & 0 & 0 & & & & & \\
\hline $\begin{array}{c}\text { Admin opiods when } \\
\text { patient complains of pain }\end{array}$ & & & 1.9 & 0.909 & 1.88 & 3 & 0.398 \\
\hline Always & 21 & 41.2 & & & & & \\
\hline Sometimes & 18 & 35.3 & & & & & \\
\hline Rarely & 9 & 17.6 & & & & & \\
\hline Never & 3 & 5.9 & & & & & \\
\hline $\begin{array}{l}\text { Admin opiods as } \\
\text { ordered by Dr }\end{array}$ & & & 2.8 & .530 & 1.20 & 2 & .305 \\
\hline Always & 43 & 84.3 & & & & & \\
\hline Sometimes & 7 & 13.7 & & & & & \\
\hline Rarely & 1 & 2.0 & & & & & \\
\hline Never & 0 & 0 & & & & & \\
\hline
\end{tabular}




\section{Continued}

\begin{tabular}{|c|c|c|c|c|c|c|c|}
\hline $\begin{array}{l}\text { Admin opiods in } \\
\text { acute then switch }\end{array}$ & & & 2.4 & 1.619 & 1.46 & 3 & 0.685 \\
\hline Always & 39 & 76.5 & & & & & \\
\hline Sometimes & 9 & 17.6 & & & & & \\
\hline Rarely & 2 & 3.9 & & & & & \\
\hline Never & 1 & 0 & & & & & \\
\hline $\begin{array}{l}\text { Tell mother pain is } \\
\text { normal after } \mathrm{C} / \mathrm{S}\end{array}$ & & & 2.2 & 1.084 & 2.24 & 3 & 0.049 \\
\hline Always & 27 & 52.9 & & & & & \\
\hline Sometimes & 12 & 23.5 & & & & & \\
\hline Rarely & 5 & 9.8 & & & & & \\
\hline Never & 7 & 13.7 & & & & & \\
\hline Total average scores & & & 2.2 & & & & \\
\hline Always & 243 & 52.94 & & & & & \\
\hline Sometimes & 120 & 26.14 & & & & & \\
\hline Rarely & 48 & 10.50 & & & & & \\
\hline Never & 48 & 10.50 & & & & & \\
\hline
\end{tabular}

Table 4. How Information Education Communication was delivered to postpartum mothers on discharge $\mathrm{N}=51$.

\begin{tabular}{|c|c|c|c|c|c|c|}
\hline & N-51 & $\%$ & $\mathrm{SD}$ & Mean & Df & $\mathrm{P}$-value \\
\hline $\begin{array}{l}\text { Whether IEC is given to PPM on } \\
\text { discharge as per Dr's orders }\end{array}$ & & & 0.497 & 1.41 & 1 & 0.080 \\
\hline Yes & 30 & 58.8 & & & & \\
\hline No & 21 & 41.2 & & & & \\
\hline $\begin{array}{l}\text { Whether IEC is given to PPM on } \\
\text { discharge verbally one to one }\end{array}$ & & & 0.385 & 1.18 & 1 & 0.401 \\
\hline Yes & 42 & 82.4 & & & & \\
\hline No & 9 & 17.6 & & & & \\
\hline $\begin{array}{l}\text { Whether IEC is given to PPM on } \\
\text { discharge verbally as a group }\end{array}$ & & & 0.440 & 1.25 & 2 & 0.530 \\
\hline Yes & 38 & 74.5 & & & & \\
\hline No & 13 & 25.5 & & & & \\
\hline $\begin{array}{l}\text { Whether IEC is given to PPM on } \\
\text { discharge by writing on a piece of paper }\end{array}$ & & & 0.272 & 1.92 & 2 & 0.862 \\
\hline Yes & 4 & 7.8 & & & & \\
\hline No & 47 & 92.2 & & & & \\
\hline $\begin{array}{c}\text { Whether IEC is given to mothers on } \\
\text { discharge by giving standardised } \\
\text { written instructions }\end{array}$ & & & 0.238 & 1.94 & 1 & 0.050 \\
\hline Yes & 3 & 5.9 & & & & \\
\hline No & 48 & 94.1 & & & & \\
\hline
\end{tabular}


post-partum women following c-section. On the average number of staff on duty at each shift, $27(52.9 \%)$ out of a total $51(100 \%)$ respondents indicated that the average number of staff at each shift on the ward was 3 - 4 while 23 (45.1\%) indicated 1 - 2 staff at each shift (P-0.077). On whether the number of staff on duty affected care of post-partum women after c-section, 46 (92.4\%) out of a total of 51 (100\%) indicated that the number of staff on duty affected care (P-0.001). Respondents were further asked on how many of them had undergone any training in postnatal care since leaving formal school. 28 (54.9\%) out of $51(100 \%)$ had additional training in postnatal care after leaving formal school and all 51 $(100 \%)$ the respondents indicated that they would benefit from a fresher course in postnatal care (Table 5).

\subsection{Availability of Materials for Care of Postpartum Women}

Respondents were asked some questions on the availability of materials on the ward for the care of postpartum women who had c-section. 47 (92.2\%) out of a total of $51(100 \%)$ respondents indicated that they did not have adequate materials for provision of care to the postpartum women who had c-section. Respondents were also asked whether they had asked the mothers or their families to bring or buy any materials for use on the woman while in the hospital, 44 (86.3\%) indicated that they had done so $(\mathrm{P}=0.085)$ and $45(88.2 \%)$ indicated that not all mothers or families would manage to bring all the materials they were asked to bring or buy. $33(64.7 \%)$ respondents indicated that they would improvise in the care of postpartum women with c-section if the family failed to

Table 5. Availability of staff for care of postpartum women $\mathrm{N}=51$.

\begin{tabular}{|c|c|c|c|c|c|c|}
\hline & $\mathbf{N}$ & $\%$ & SD & Mean & Df & $P$-value \\
\hline $\begin{array}{l}\text { Average number of staff } \\
\text { on duty at each shift }\end{array}$ & & & 1.57 & 0.539 & 2 & 0.077 \\
\hline $1-2$ & 23 & 45.1 & & & & \\
\hline $3-4$ & 27 & 52.9 & & & & \\
\hline $5-6$ & 1 & 2.0 & & & & \\
\hline $\begin{array}{l}\text { Does the number of staff } \\
\text { affect care of PPM }\end{array}$ & & & 1.10 & 0.300 & 1 & 0.001 \\
\hline Yes & 46 & 90.2 & & & & \\
\hline No & 5 & 9.8 & & & & \\
\hline $\begin{array}{l}\text { If midwives had received any additional } \\
\text { training in PNC after leaving school }\end{array}$ & & & 1.45 & 0.503 & 1 & 0.979 \\
\hline Yes & 28 & 54.9 & & & & \\
\hline No & 23 & 45.1 & & & & \\
\hline $\begin{array}{l}\text { If Midwife would benefit from a } \\
\text { refresher course in PNC }\end{array}$ & & & & 1.00 & 0.000 & \\
\hline Yes & 51 & 100.0 & & & & \\
\hline No & 0 & 0 & & & & \\
\hline
\end{tabular}


bring the requested materials and $3(5.9 \%)$ mentioned that they would delay the discharge of the postpartum women $(\mathrm{P}=0.094) .14(27.5 \%)$ out of $51(100 \%)$ respondents indicated that they had at some point failed to offer care due to none availability of materials (Table 6).

\subsection{Home/Domiciliary Visits for Postpartum Mothers with Complicated Deliveries}

Respondents were asked whether follow-up of postpartum women who had complicated labour and delivery including c-section after discharge in their homes was being conducted. Almost all 50 (98\%) out of 51 (100\%) indicated that postpartum women with complicated delivery including c-section were not followed up in their homes after discharge to check on their condition. Only 19 $(37.3 \%)$ out of $50(100 \%)$ had recommended the postpartum women mainly to visit their nearest local clinic or the maternal child health department in the same hospital in case of any problems (Table 7).

\section{Discussion}

Postnatal care should be delivered in the most appropriate setting, whether that is in hospital or in the woman's home, it is imperative that the care provided is

Table 6. Availability of materials for care of postpartum women $\mathrm{N}=51$.

\begin{tabular}{|c|c|c|c|c|c|c|}
\hline & $\mathbf{N}$ & $\%$ & Mean & SD & Df & P-value \\
\hline $\begin{array}{c}\text { Do you have adequate materials for } \\
\text { provision of care }\end{array}$ & & & 1.92 & 0.272 & 1 & 0.862 \\
\hline Yes & 4 & 7.8 & & & & \\
\hline No & 47 & 92.2 & & & & \\
\hline $\begin{array}{c}\text { If mother/family asked to bring/buy } \\
\text { any materials for use }\end{array}$ & & & 1.14 & 0.348 & 2 & 0.085 \\
\hline Yes & 44 & 86.3 & & & & \\
\hline No & 7 & 13.7 & & & & \\
\hline $\begin{array}{c}\text { Do all mothers manage to bring all } \\
\text { materials requested }\end{array}$ & & & 2.04 & 0.344 & 2 & 0.197 \\
\hline Yes & 2 & 3.9 & & & & \\
\hline No & 45 & 88.2 & & & & \\
\hline $\begin{array}{l}\text { What is done if mothers do not } \\
\text { manage to bring material requested }\end{array}$ & & & 1.69 & 1.191 & 2 & 0.094 \\
\hline Improvise & 33 & 64.7 & & & & \\
\hline Hospital provides & 10 & 19.6 & & & & \\
\hline Delay their discharge & 3 & 5.9 & & & & \\
\hline $\begin{array}{l}\text { If any time HCP failed to offer } \\
\text { service due to no m/s supplies }\end{array}$ & & & 1.73 & 0.203 & 1 & 0.437 \\
\hline Yes & 14 & 27.5 & & & & \\
\hline No & 37 & 72.5 & & & & \\
\hline
\end{tabular}


Table 7. Home/domiciliary visits for postpartum mothers with complicated labour and deliveries (CLD) $\mathrm{N}=51$.

\begin{tabular}{|c|c|c|c|c|c|c|}
\hline & $\mathbf{N}$ & $\%$ & Mean & $\begin{array}{l}\text { Standard } \\
\text { deviation }\end{array}$ & $\mathrm{DF}$ & $P$-value \\
\hline $\begin{array}{l}\text { If PPM with complicated labour and } \\
\text { delivery are followed up in their homes } \\
\text { to check their condition after discharge }\end{array}$ & & & 1.98 & 0.140 & 1 & 0.596 \\
\hline Yes & 1 & 2.0 & & & & \\
\hline No & 50 & 98.0 & & & & \\
\hline $\begin{array}{c}\text { If Midwife has ever made a domiciliary } \\
\text { visit for PPM with complicated labour } \\
\text { and delivery }\end{array}$ & & & 1.98 & 0.140 & 2 & 0.613 \\
\hline Yes & 1 & 2.0 & & & & \\
\hline No & 50 & 98.0 & & & & \\
\hline $\begin{array}{l}\text { If Midwife has ever recommended a PPM } \\
\text { with complicated labour and delivery for } \\
\text { a Dom visit to any dept }(\mathrm{N}=50)\end{array}$ & & & 1.65 & 0.522 & 3 & 0.437 \\
\hline Yes & 19 & 37.3 & & & & \\
\hline No & 31 & 60.8 & & & & \\
\hline
\end{tabular}

of the highest standard and meets the needs of the individual [22]. The study focused on care of the postpartum women who undergo c-sections and admitted in the postnatal wards up to discharge from the hospital. In the study, midwives, being the respondents assessed themselves on the care they give to postpartum women.

The demographic characteristics have indicated that the midwifery profession is still very much female oriented as all the respondents were female. This situation may not just be peculiar to UTH or Zambia alone as many studies have found similar results. The numbers of male nurse world over are much fewer than those of the females. In the United Kingdom, Men make up 10.6 percent of the total nursing work force and only 0.4 percent are midwives, whereas in Iceland and China men only make up 1 percent [23] [24]. The situation may be different in Italy, Israel, Kenya and Saudi Arabia where the percentages of male nurses range from 20 to 32 percent of the total nursing workforce. Studies in Jamaica and Uganda have also indicated similar findings though it has also been acknowledged that there is some marginal increase in the numbers compared to what has been there before [24] [25] [26] [27].

\subsection{Post Operative Care of Caesarean Section Postpartum Mothers}

Health services should ensure women and their babies have access to safe, high-quality maternity services. Whether postnatal care is provided in hospital or in the woman's home, it is imperative that the care provided is of the highest standard and meets the needs of the individual. For women who have undergone 
a caesarean section, postnatal care is important to prevent and, where necessary, treat infection and post-birth complications. This is because the risk of infection and complications from surgery are potentially dangerous, particularly in settings that lack the facilities and/or capacity to properly conduct safe surgery [17] [22].

Midwives were asked to score themselves on a 4 point Likert scale (always-3, sometimes-2, rarely -1 and never-0) on the various items which constitute immediate and subsequent post-operative care of the post partum mothers after undergoing c-section. Midwives scored themselves very high on "always" performing all immediate post-operative caring activities with an average score of 2.9 on a 4 point Likert scale. However, the scores were low on always performing subsequent post-operative caring activities with an average score of 1.7 on a 4 point Likert scale. The activities in the subsequent post-operative period are those which mothers would perform for themselves if they were in good condition to do so but given their current situation they could not and therefore relied on the health care providers as they had just undergone major abdominal surgery.

The findings of the current study are similar to those obtained by [28], where post c-section women expressed concerns that the care and assistance they received were not satisfactory as they described it to be uncaring, neglectful and disappointing because they were not assisted to perform certain activities while they were still in pain and sick. However, another study [29] revealed that mothers were satisfied with all the post operative care they received except in the information area. Another study by [30] on experiences of mothers and nursing staff on post c-section pain showed that nursing staff and mothers viewed post-operative pain differently. Nurses viewed pain in a casual way that it did not hurt as much as the mothers were displaying because pain was in levels, whereas mothers indicated that the post operative pain was so intense especially after recovery from an aesthesia and nursing staff had a very casual way of dealing with postpartum pain. Mothers were therefore left to do certain activities by themselves even when they were in pain.

\subsection{Post Operative Pain Management}

High-quality pain relief is important after cesarean section to promote early recovery and optimize mothers' ability to care for themselves and their newborns. Despite advances in postoperative pain management, postoperative pain relief and satisfaction are still inadequate in some patients because of individual variability and limitation from side effects of analgesic drugs or techniques [31].

Midwives in this study were asked to indicate how often and the different ways they managed post-operative pain for women following c-section using a 4 point Likert Scale. The different ways of pain management which were significantly associated with pain relief in the post-operative period were relaxation/diversional techniques, reassuring the mother, telling the mother that pain 
was normal after a c-section and administering opiods before recovery from anaesthesia. However, though not significantly associated with pain management, 84.3 percent of Midwives indicated that they always administered opiods according to the doctor's orders, 76.5 percent always administered opiods in the acute stage and switched to lesser stronger ones later and 74.5 percent always administered opiods immediately after patient recovered from effects of anaesthesia. Studies have shown that more than 80 percent of patients who undergo surgical procedures experience acute postoperative pain and approximately 75 percent of those with postoperative pain report the severity as moderate, severe, or extreme. Evidence suggests that less than half of patients who undergo surgery report adequate postoperative pain relief [31] [32]. Inadequately controlled pain negatively affects quality of life, function, and functional recovery, the risk of post-surgical complications, and the risk of persistent postsurgical pain [31] [32]. Another study highlighted that 91 percent of c-section women required opiods with a median time to stopping the opiods of nine days. The median time for stopping all painkillers was 16 days, and pain resolved in a median of 21 days [33]. An observational study to assess the effectiveness of postoperative pain management of patients undergoing elective cesarean section found that postoperative pain management was adequate in terms of patients' safety but it was not effective according to the goal set by Joint Commission on Accreditation of uniformly low pain score of not more than 3 out of 10 both at rest and with movement. It was therefore recommended that an ideal post-cesarean analgesic regimen requires proper utilization of resources to formulate a method which is cost effective, simple to implement, and has minimal impact on staff workload [34]. There are high demands on staff to provide pain relief that is beneficial to both the women and the newborn [35].

\subsection{Mode of Information Education and Communication Delivery to Postpartum Women after Caesarean Section}

Women should be given appropriate and consistent written and verbal information and education relating to the postnatal period and what is to be expected of them. This enables women to make informed decisions regarding their care and the care of their baby, and can increase women's confidence and satisfaction with the care provided [36]. In the study, Midwives were asked on the different ways they delivered IEC to c-section postpartum women on discharge from the postnatal wards. The IEC given to mothers by giving a standardized written instructions was found to be significantly associated with the provision on IEC to postpartum mothers on discharge $(\mathrm{P}=0.050)$ (Table 4$)$. The study found that majority of Midwives gave IEC to postpartum verbally either on one to one $(82.4 \%)$ or as a group $(74.5 \%)$.

Many women report lower levels of satisfaction with the care and support they receive during the postnatal period than at any other phase of their maternity care. Feeling listened to and well supported, and receiving timely and consistent information are important factors contributing to women's satisfaction with 
their postnatal care. Providing information and education relating to the normal physiological changes associated with childbirth, breastfeeding and parenting is a key component of postnatal care that is aimed at giving women and their families the confidence to manage the care of their baby. It should be easy to understand and communicate in the woman's primary language. Women should also be given the opportunity to discuss and ask questions about the information provided by a midwife and/or doctor [23]. Where appropriate and determined by the woman, written information and education should be provided to her family and/or significant others. It is concluded that maternal health education imparted at the right time and in a simplistic manner using a simple written module can significantly reduce the burden of infant mortality [37] [38].

\subsection{Availability of Staff and Materials for Care of Postpartum Mothers}

Health services should ensure that health professionals employed to deliver postnatal care are appropriately qualified, credentialed and in correct ratios. A qualified and skilled workforce is imperative to the provision of safe and high-quality postnatal care that reflects current, evidence-based practices. In the study, Midwives were asked on staffing levels for care of postpartum women in the postnatal wards in order to gauge the care they provided to patients. A significant association was found between the number of staff on duty and the care provided to postpartum mothers in the postnatal wards in the UTH-NW (P = 0.001). 52.9 percent indicated that the number of staff on duty per shift ranged between 3 - 4, while 45.1 percent indicated that the number of midwives on duty per shift ranged from 1 - 2 staff. The study further revealed that only 54.9 percent of Midwives had additional training on postnatal care since leaving their formal training as Midwives and they all expressed great interest in affording them refresher courses.

The findings of the study are very much in line with others findings elsewhere. A study on Cesarean delivery rate and staffing levels of the maternity unit found a statistically significant association between staffing levels of the maternity unit and cesarean delivery use. Independently of all other characteristics, staffing levels for obstetricians and midwives had a significant impact on the use of intrapartum and elective cesarean deliveries [39]. Furthermore, other studies have found that low staffing levels in maternity wards lead to high percentages of women being delivered by c-section as staff do not have enough time to encourage and keep on monitoring women who may be susceptible to complications. It was estimated that $\mathrm{C}$-sections for first-time mothers could be reduced by about 34 percent if situations of low-staffing were avoided. This would be a very important achievement given the already overly high rates of $\mathrm{C}$-sections around developed countries [39] [40] [41]. These findings are very relevant to this study because c-section patients are nursed in postnatal wards which equally have very low numbers of Midwives to offer quality post-operative care for the postpartum women. 
Care for postpartum women may also be affected by problems of availability of resources such as medical equipment and materials. Midwives were asked whether they had adequate materials for use on postpartum women who had complicated deliveries including c-section women. Majority (92.2\%) of Midwives indicated that they did not have adequate materials for use and $86.2 \%$ indicated that they have at times asked the mothers/families to either bring from home or buy though $88.2 \%$ also indicated that there were instances when mothers/families were not able to provide the items requested to buy or bring for their care while still admitted on the postnatal ward. However, $64.7 \%$ of the midwives indicated that they had never failed to provide the necessary care to the postpartum women because of unavailability of materials as they would always improvise but in some instances, they would delay the discharge of the women.

\subsection{Follow-Up of Postpartum Mothers after Discharge}

The days and weeks following childbirth, the postnatal period-is a critical phase in the lives of mothers and newborn babies especially those who had complicated labour and delivery including c-section. This is because major changes occur during this period which determines the well-being of mothers and newborns. Lack of appropriate care during this period could result in significant ill health and even death. Most maternal and infant deaths occur during this time [7].

In the study, Midwives were asked whether postpartum women who had complicated deliveries including c-section were followed up in their homes after discharge from the hospital and 98 percent stated that postpartum women were not visited in their homes after discharge and 98 percent of midwives had never conducted a home visit or domiciliary visit. Midwives were further asked whether they had ever recommended any postpartum mother with complicated labour and delivery anywhere for follow up. Only $37.3 \%$ indicated that they had recommended some mothers with complicated deliveries for follow up to the Maternal and Child Health department within the hospital and to the nearest urban clinic.

It is recommended that home visits within the first seven days after discharge from the maternity hospital, and within the first three days when the newborn is classified as high risk should be undertaken. In women's care, home visits are used to know the conditions of childbirth, assess the health status of the mothers, mother-child interaction and the return of the mother's organism to pre-pregnancy conditions, verify emotional and social conditions, identify risk situations and complications to adopt the correct conduct, support breastfeeding, provide advice on self-care for the mother [7] [42]. In addition, another study revealed that providing postpartum home visit can influence postpartum depression in a positive way and could improve mothers' and infants' health [43]. Therefore, as a minimum requirement, following discharge, public health services should offer women at least one postnatal visit in the first week after delivery, which has a great impact on maternal adaptation to the new conditions, 
as the most critical problems after delivery occur in the first 10 days. The study further recommended that health services should ensure that all health professionals providing postnatal home-based care should have undertaken adequate training to make decisions regarding the safety of the environment in which they are to provide care [43] [44].

\section{Conclusion}

It is apparent that midwives perform highly skilled roles in difficult circumstances, yet they find meaning and satisfaction in their work. While the findings regarding postnatal care may be perceived as gloomy in some areas, it is important to reflect on this as a judicious time for ward managers and midwives to demand for the requisites for provision of quality midwifery care to women who have had complicated deliveries including c-sections and postnatal care in general.

\section{Implication for Practice}

The results of the study will contribute to the body of nursing and midwifery knowledge through new understanding of the familiar situation and generation of new knowledge. As many women continue to deliver by c-section, Midwives need to always endeavour to provide quality care from the time the woman comes from theatre till discharge. IEC written down in a standardized format for reference should be embraced as well as domiciliary visits.

It is also important to understand the factors that affect delivery of quality care to postpartum mothers and patients in general as service factors such as low staffing levels, inadequate materials to use and also knowledge levels of health providers so that such situations could be addressed. It is envisage that continued dissemination of this information in many relevant settings in Zambia and abroad will promote interest in possibilities for improvement in health care provision.

\section{Limitation of the Study}

The study used respondents to rate and report their own care delivered to the postpartum mothers, it is possible that circumstances could have risen where respondents could have rated themselves high or low. This is despite the fact that several studies have proved that nurses are reliable and valid informants on the care they provide in the hospital. The study using the 4 point Likert scale only assessed how often Midwives performed the caring activities and not how well they performed the activities. It is therefore recommended that another study in which postpartum women are informants should be undertaken so that comparisons could be made on the care provided to postpartum women after a C-Section delivery.

\section{Acknowledgements}

We would like to acknowledge the financial support provided by the Norwe- 
gian Agency for Development (NORAD) through the NORHED QZA-0848 QZA-MW-13/00032 Grant.

\section{Source of Funding}

Norwegian Agency for Development (NORAD) through the NORHED QZA-0848 QZA-MW-13/00032 Grant should be at the end.

\section{Conflicts of Interest}

The authors have not declared any conflict of interests.

\section{References}

[1] Dippenaar, J and Da Serra, D. (2013) Seller's Midwifery. 2nd Edition, Juta, Lansdowne.

[2] Hoque, M. and Klein, M. C. (2011) Incidence of Obstetric and Foetal Complications during Labor and Delivery at a Community Health Centre, Midwives Obstetric Unit of Durban, South Africa. ISRN Obstetrics and Gynecology, 2011, Article ID: 259308.

[3] Rahman, A., Ali, A. and Anwar, I. (2017) Indications and Determinants of Caesarean Section Delivery: Evidence from a Population-Based Study in Matlab, Bangladesh. PLoS One, 12, e0188074.

[4] Office on Women's Health (2017) Pregnancy Labor and Birth. U.S. Department of Health and Human Services.

[5] Madhukar, P. (2000) Medical Interventions: Caesarean Sections as a Case Study. Economic and Political Weekly, 35, 2755-2761.

[6] Gynaecworld (2008) Why Are Caesareans Done? Gynaecworld, Mumbai.

[7] World Health Organisation (2013) Recommendations on Postnatal of the Mother and Newborn. WHO Library Cataloguing in Publication Data.

[8] Saleem, S., McClure, E.M., Goudar, S.S., et al. (2014) A Prospective Study of Maternal, Foetal and Neonatal Deaths in Low and Middle Income Countries. Bulletin of the World Health Organization, 92, 605-612. https://www.ncbi.nlm.nih.gov/pmc/articles/PMC4147405/

[9] Lohela, T.J., Campbell, O.M.R. and Gabrysch, S. (2012) Distance to Care, Facility Delivery and Early Neonatal Mortality in Malawi and Zambia. PLoS ONE, 7, e52110.

[10] Ngozi, J., Tornes, Y.F., Mukasa, P.K., Salongo, W., Kabakyenga, J., Sezalio, M., Wouters, K., Jacqueym Y. and Geertytuyden, J.V. (2016) Puerperal Sepsis, the Leading Cause of Maternal Deaths at a Tertiary University Teaching Hospital in Uganda. Journal of BMC Pregnancy Childbirth, 16, 207.

[11] Warren, C.E. (2015) Exploring the Quality and Effect of Comprehensive Postnatal Care Models in East and Southern Africa. International Centre for Reproductive Health.

[12] University Teaching Hospital-Women and Newborn (2018) Integrated Provincial Meeting Report. University Teaching Hospital-Women and Newborn, Lusaka.

[13] University Teaching Hospital-Women and Newborn (2017) Integrated Provincial Meeting Report. University Teaching Hospital-Women and Newborn, Lusaka.

[14] Central Statistical Office, Ministry of Health (Zambia), ICF International (2014) 
Zambia Demographic and Health Survey 2013-14. Central Statistical Office, Ministry of Health, and ICF International, Rockville, Maryland, USA.

[15] Yaya S, Uthman O.A, 2 , Amouzou A, and Bishwajit G. (2018) Disparities in Caesarean Section Prevalence and Determinants Across Sub-Saharan Africa Countries. Global Health Research and Policy, 3, 19.

[16] Mukeshimana, M.J. (2012) Post-Caesarean Complication at the University Teaching Hospital, Lusaka.

[17] Skelton, P. The First 24 Hours after Caesarean. https://www.kiwifamilies.co.nz/articles/the-first-24-hours-after-caesarean/

[18] World Health Organization (2015) WHO Statement on Caesarean Section Rates. Department of Reproductive Health and Research, World Health Organization. http://41.77.4.165:6510/apps.who.int/iris/bitstream/10665/161442/1/WHO_RHR_1 5.02_eng.pdf

[19] Yeniel, A.O. and Petri, E. (2014) Pregnancy, Childbirth, and Sexual Function: Perceptions and Facts. International Urogynecology Journal, 25, 5-14. https://doi.org/10.1007/s00192-013-2118-7

[20] Aiken, L. and Patrician, P. (2000) Measuring Organizational Traits of Hospitals: The Revised Nursing Working Index. Nursing Research, 49, 146-153. https://doi.org/10.1097/00006199-200005000-00006

[21] McHugh, M.D. and Stimpel, A.W. (2012). Nurse Reported Quality of Care: A Measure of Hospital Quality. Research in Nursing and Health, 35, 566-575. https://doi.org/10.1002/nur.21503

[22] State government Victoria (2012) Postnatal Care Program Guidelines for Victorian Health Services. Department of Health, Melbourne, Victoria.

[23] Regan, H. (2012) Male Nurses Worldwide. https://realmanswork.wordpress.com/2012/05/05/male-nurses-worldwide/

[24] Jones, D. (2017) Male Midwives: How Men Are Changing the Rules https://www.totaljobs.com/insidejob/male-midwives-men-changing-rules/

[25] Achora, S. (2016) Conflicting Image: Experience of Male Nurses in a Uganda's Hospital. International Journal of Africa Nursing Sciences, 5, 24-28. https://doi.org/10.1016/j.ijans.2016.10.001

[26] Campbell, A. (2018) Gender Disparity in Nursing and Midwifery in Jamaica: Time for Action.

http://www.jamaicaobserver.com/opinion/gender-disparity-in-nursing-and-midwif ery_in_Jamaica:_Time_for_Action_132605

[27] Kouta, C. (2011) Gender Discrimination and Nursing: A Literature Review. Journal of Professional Nursing, 27, 59-63. https://doi.org/10.1016/j.profnurs.2010.10.006

[28] Jikijela, T.P., James, S. and Sonti, B.S.I. (2018) Caesarean Section Deliveries: Experiences of Mothers of Midwifery Care at a Public Hospital in Nelson Mandela Bay. Curationis, 41, a1804. https://doi.org/10.4102/curationis.v41i1.1804

[29] Azari, S., Sehaty, F. and Ebrahimi, H. (2013) Satisfaction of Women from Cesarean Section Care Services in Public and Private Hospitals of Tabriz. Iranian Journal of Nursing and Midwifery Research, 18, 435-438.

[30] Sell, S.E., Beresford, P.C., Ribas Dias, H.H.Z., Zigelli Garcia, S.R. and Atherino dos Santos, E.K. (2012) [Looks and Knowledge: Experiences of Mothers and Nursing Staff Regarding Post-Caesarean Section Pain]. Texto \& Contexto-Enfermagem, 21, 766-774. https://doi.org/10.1590/S0104-07072012000400006

[31] Gan, T.J., Habib, A.S., Miller, T.E., White, W. and Apfelbaum, J.L. (2014) Incidence, 
Patient Satisfaction, and Perceptions of Postsurgical Pain: Results from a US National Survey. Current Medical Research and Opinion, 30, 149-160. https://doi.org/10.1185/03007995.2013.860019

[32] The American Pain Society (2016) Guidelines on the Management of Postoperative Pain. The Journal of Pain, 17, 131-157.

[33] American Society of Anesthesiologists (2017) Evidence-Based Approach to Treating Post-Delivery Pain in New Moms during Opioid Crisis. ScienceDaily. www.sciencedaily.com/releases/2017/11/171114092050.htm

[34] Ismail, S., Shahzad, K. and Shafiq, F. (2012) Observational Study to Assess the Effectiveness of Postoperative Pain Management of Patients Undergoing Elective Cesarean Section. Journal of Anaesthesiology Clinical Pharmacology, 28, 36-40. https://doi.org/10.4103/0970-9185.92432

[35] Niklasson, B. (2015) Pain Relief Following Cesarean Section-Short and Long Term Perspectives. Karolinska Institutet, Stockholm, Sweden.

[36] Newburn, M. and Bhavnani, V. (2010) Left to Your Own Devices: The Postnatal Care Experience of 1260 First-Time Mothers. NCT, London

[37] Mirzaee, K., Ghadikolaee, S.O., Shakeri, M.T. and Bazzaz, M. (2015) Maternal Knowledge on Postpartum Care in Healthcare Centers of Mashhad, Iran in 2013. Journal of Midwifery and Reproductive Health, 3, 456-464.

[38] Yashaswi, P., Prabhu, K.M. and Angolkar, M.B. (2017) Impact of Health Education on Knowledge of Newborn Care among Expectant Women in Urban Area of Belagavi, India: Pre and Post Study. International Journal of Contemporary Medical Research, 4, 305-308.

[39] Zbiri, S., Rozenberg, P., Goffinet, F. and Milcent, C. (2018) Cesarean Delivery Rate and Staffing Levels of the Maternity Unit. PLoS ONE, 13, e0207379. https://doi.org/10.1371/journal.pone.0207379

[40] Alexander, D., et al. (2013), Does Physician Compensation Impact Procedure Choice and Patient Health? Technical Report.

[41] Allin, S., Baker, M., Isabelle, M. and Stabile, M. (2015) Physician Incentives and the Rise in C-Sections: Evidence from Canada. Technical Report, National Bureau of Economic Research. https://doi.org/10.3386/w21022

[42] Bezerra Silva, L.L., Oliveira Feliciano, K.V., Pacheco Oliveira, L.N.F., Pedrosa, E.N., Medeiros Corrêa, M.S. and Souza, A.I. (2016) Women's Care during Home Visits for the "First Comprehensive Healthcare Week". Revista Gaúcha de Enfermagem, 37, e59248.

[43] Milani, S.H., Amiri, P., Mohsey, M., Monfared, E.D., Vaziri, S.M., Malekkhahi, A. and Salmani, F. (2017) Effect of Health Care as the "Home Visiting" on Postpartum Depression: A Controlled Clinical Trial. International Journal of Preventive Medicine, 8, 20. https://doi.org/10.4103/2008-7802.204003

[44] Heyward, K.L. (2013) An Exploration of the Role and Experiences of the Postnatal Domiciliary Midwife in Victoria, Australia. Master Thesis, Australian Catholic University, Australia. 